\title{
SEASONAL DROUGHT DYNAMICS IN EL-BEHEIRA GOVERNORATE, EGYPT
}

\author{
${ }^{1,2}$ Amr Mossad, ${ }^{3}$ Hazem S. Mehawed and ${ }^{4}$ Ahmed El-Araby \\ ${ }^{1}$ Department of Agricultural Engineering, Faculty of Agriculture, Ain Shams University, Cairo, Egypt \\ ${ }^{2}$ Department of Agricultural Engineering, College of Food and Agricultural Sciences, \\ King Saud University, Riyadh, Kingdom of Saudi Arabia \\ ${ }^{3}$ Agricultural Engineering Research Institute, Agricultural Research Center, Ministry of Agriculture, Cairo, Egypt \\ ${ }^{4}$ Department of Soil Science, Faculty of Agriculture, Ain Shams University, Cairo, Egypt
}

Received 2014-02-25; Revised 2014-03-04; Accepted 2014-04-04

\begin{abstract}
Drought is the most damaging climate-related hazards due to the prolonged absence of precipitation. Therefore, understanding the drought dynamics is important for irrigation water management to mitigate the negative impacts on agriculture. In this study, Standardized Precipitation Index (SPI) and Standardized Precipitation Evapotranspiration Index (SPEI) were used as effective tools for tracking the changes of water status occurred at five agro-meteorological stations (Etay Al Baroud, Wadi El-Natrun, Al Boseli, Badr and Nubariyah) within El-Beheira governorate, Egypt. In addition, the overall water risk for agro-meteorological stations was estimated using the Aqueduct-GIS tool. The results clarified that Badr agro-meteorological station is representing the highest of water deficit by $96.6 \%$, whereas, Al Boseli agro-meteorological station is representing the lowest water deficit by $86.9 \%$. However, The SPI over El-Beheira region often confined in the near normal class, while the SPEI showed a notable increase of drought (SPEI $=0$ to -4 ) in last 10 years of the analyses. The results suggested that El-Beheira governorate is moving toward the drought in general and Wadi El-Natrun and Nubariyah are the most drought affected areas in the future.
\end{abstract}

Keywords: GIS, Hydrology, Precipitation, Evapotranspiration, SPI, SPEI

\section{INTRODUCTION}

Drought is one of the most frequent natural hazards affecting the globe, mainly associated with a decrease in precipitation in wide regions around the world (González-Hidalgo et al., 2009). This reflected negative impacts on agriculture, water resources and ecosystems (Vicente-Serrano, 2006; López-Moreno et al., 2009). Agriculture is an affected sector by the drought due to its dependence on precipitation during plant growing stages. Global warming has a notable impact as a consequence of water loss and increasing evapotranspiration, (Loukas et al., 2007). Accordingly, Drought is a temporary imbalance in water availability related to precipitation lower than the required averages and it occurs in most climatic regions with various frequencies, severity and duration. Studies related to the change of the precipitation were performed in different places around the world (Samdi and Zghoul, 2006; Hamdi et al., 2009; Al-Qudah and Smadi, 2011; Gao and Hou, 2012).

Typically, drought phenomenon is categorized into four major classes: Meteorological, agricultural, hydrological and socio-economical (Heim, 2002). Meteorological drought is identified by lack of precipitation as the main indicator, while agricultural drought is related to the total soil moisture deficit. However, hydrological drought is characterized by shortage of stream flow, as well as ground water supplies. This phenomenon is usually described using drought detection and monitoring indices which are based on different natural variables in a given time intervals such as precipitation, soil moisture, potential

Corresponding Author: Amr Mossad, Department of Agricultural Engineering, Faculty of Agriculture, Ain Shams University, P.O. Box: 68 Hadaekshoubra, 11241 Shoubra Cairo, Egypt Tel: +2 01018966147 Fax: +2-02 44444460 
evapotranspiration, vegetation condition, ground water and surface water (Mishra and Singh, 2010). The drought analysis via different drought-causative and droughtresponsive parameters was developed by many scientists (Gibbs and Maher, 1967; Palmer, 1968; Shafer and Dezman, 1982; McKee et al., 1993; Mimikou et al., 1993; Kogan, 2002; Keyantash and Dracup, 2004).

McKee et al. (1993) had proposed the Standardized Precipitation Index (SPI) as a drought indicator for meteorological drought classify, monitor and analysis dryness-wetness tool, which is widely applied to characterize extreme dryness or wetness. The SPI is recommended by the World Meteorological Organization (WMO) as a standard drought monitoring index (Hayes et al., 2011). Recently the SPI was used at different locations in the world (Svoboda et al., 2002; Valentina et al., 2008; Shukla and Wood, 2008; Mo, 2011). SPI simplicity and temporal flexibility are the reasons for its wide application. However, its weakness that doesn't have soil water-balance component, thus no ratio of evapotranspiration/potential evapotranspiration can be calculated. Therefore, a new version of the index called Standardized Precipitation Evapotranspiration Index (SPEI) was developed by (Vicente-Serrano et al., 2010) attempts to consider the Potential Evapotranspiration (PET) in the calculations. The SPEI meets the requirements of a drought index, as indicated by Nkemdirim and Weber (1999); SPEI could be used by different scientific disciplines to detect, monitor and analyze drought due to its multi-scalar character. However, a crucial advantage of the SPEI over the more widely used drought indices that consider the effect of PET on drought severity is that its multi-scalar characteristic enables the identification of different drought types and effects in the context of global warming (Vicente-Serrano et al., 2010).

The objectives of this research were to apply the 12time scales of SPI and SPEI as good tools to analyze and assess the rainfall anomalies and behavior of droughts during 60 years (1950-2010) for five sites using agrometeorological stations within El-Beheira governorate in the north of Egypt. In addition, digital maps of the average magnitude of drought were manipulated for the selected regions over a certain period of time using the Geographic Information System (GIS).

\section{MATERIALS AND METHODS}

\subsection{Data Collection and Analysis}

This study was performed on five locations (Etay Al Baroud, Wadi El-Natrun, Al Boseli, Badr and
Nubariyah), At El-Beheira governorate north of Egypt; the coordinates of the study sites are shown in Table 2. The available monthly records of precipitation, maximum and minimum air temperature for the locations were obtained from the Global Precipitation Climatology Center (GPCC, 2013) within the period of 1950-2010. The climatic data sourced from GPCC were compared with the data from Central Lab of Agro-Climatology (CLAC), ministry of agriculture and land reclamation within the period of 1997-2010. The quality of annual precipitation records was investigated through nonparametric tests. Randomness, homogeneity and absence of trends were tested using the Kendall autocorrelation test, the Mann-Kendall trend test and the homogeneity tests of Mann-Whitney for mean and variance (Helsel and Hirsch, 1992). When the hypothesis of homogeneity fails (significance level 0.05), data series was corrected by the method of cumulative residuals (Allen et al., 1998). The missing climatic data were estimated from nearby stations using linear regression. The overall water risk, drought severity and ground water stress were obtained by using the Aqueduct, which is an online Geographic Information System (GIS) tool build by the world resources institute (Aqueduct GIS, 2013).

\subsection{Drought Indices Models}

\subsubsection{SPI Mathematical Model}

The SPI was estimated per 12 month period for ElBeheira. The calculation of SPI based on equal probability transformation. Monthly precipitation transformed to a standard normal distribution to yield SPI values by preserving probabilities. This procedure ensures seasonal uniform data under different climate regimes. The following methodology was applied for calculating SPI according to (McKee et al., 1993). First step is to find the Probability Distribution Function (PDF) that describes the distribution of the precipitation data over time. The PDF was selected properly through L-moments ratios diagrams (Hosking and Wallis, 1997). Consequently, the gamma probability density function with two parameters was applied to estimate the pertinent parameters using the maximum likelihood approach (Sprent and Smeeton, 2001). The continuous random variable $\mathrm{x}$ follows the gamma distribution if the PDF of $\mathrm{x}$ is:

$$
g(x)=\frac{1}{\beta^{\alpha} \Gamma(\alpha)} \cdot x^{\alpha-1} e^{-x / \beta}
$$

This is for $\mathrm{x}>0$, otherwise $\mathrm{g}(\mathrm{x})=0$; where the parameters $\alpha$ and $\beta$ satisfy $\alpha>0, \beta>0$. But for $\alpha>0$ gamma function $\Gamma(\alpha)$ is defined by: 


$$
\Gamma(\alpha)=\int_{0}^{\infty} x^{\alpha-1} e^{-x} d x
$$

The parameters $\alpha$ and $\beta$ required to adjust the gamma distribution with the data set which was estimated using the maximum likelihood estimation as follows:

$$
\begin{aligned}
& \alpha=\frac{1}{4 \mathrm{~A}}\left(1+\sqrt{1+\frac{4 \mathrm{~A}}{3}}\right) \\
& \beta=\frac{\mathrm{x}}{\alpha} \\
& \mathrm{A}=\ln (\overline{\mathrm{x}})-\frac{\sum \ln (\mathrm{x})}{\mathrm{n}}
\end{aligned}
$$

where, $\mathrm{n}$ is the number of precipitation observation of the data set. By integrating PDF with respect to $\mathrm{x}$ and attach $\alpha$ and $\beta$ parameters, the cumulative probability distribution function $\mathrm{G}(\mathrm{x})$ will be obtained as follows:

$$
G(x)=\int_{0}^{x} g(x) d x=\frac{1}{\beta^{\alpha} \Gamma(\alpha)} \int_{0}^{x} x^{\alpha-1} e^{-x / \beta} d x
$$

Incase $\mathrm{x} / \beta=\mathrm{t}$, the incomplete gamma function will be as:

$$
G(x)=\frac{1}{\Gamma(\alpha)} \int_{0}^{x} t^{\alpha-1} e^{-t} d t
$$

The gamma distribution is undefined for $\mathrm{x}=0$ and $\mathrm{q}$ $=\mathrm{P}(\mathrm{x}=0)>0$, where $\mathrm{P}(\mathrm{x}=0)$ is the probability of zero (null) precipitation. Therefore, cumulative probability distribution function becomes:

$$
H(x)=q+(1-q) \cdot G(x)
$$

Finally, the spatial representation of SPI values was drawn for each 2 years stared by 1950 until 2010 using Surfer 8 software packages. Local fit technique was used for estimating the grid points onto the surface form scattered observations according to Kriging method. The results of the SPI were compared with the reference intervals and classes as in Table $\mathbf{1}$.

\subsubsection{SPEI Mathematical Model}

The calculation of SPEI in this study was based on the original SPI calculations and takes into account the PET. Therefore SPI values were used as input data based on the probability distribution of different Precipitation and Potential Evapotranspiration (P-PET) accumulated over a 12 month time frame. Potential
Evapotranspiration, (PET) was estimated according to Thornthwaite (1948) as follows:

$$
\mathrm{PET}=16 \mathrm{~K}\left(\frac{10 \mathrm{~T}}{\mathrm{I}}\right)^{\mathrm{m}}
$$

where, $\mathrm{T}$ is the monthly mean temperature $\left({ }^{\circ} \mathrm{C}\right), \mathrm{I}$ is a heat index, which is calculated as the sum of 12 monthly index values; $m$ is a coefficient depending on:

$$
\mathrm{I}: \mathrm{m}=6.75 \times 10^{-7} \mathrm{I}^{3}-7.71 \times 10^{-5} \mathrm{I}^{2}+1.79 \times 10^{-2} \mathrm{I}+0.492
$$

And $\mathrm{K}$ is a correction coefficient computed as a function of latitude and month, Table 1 indicates the Categorization of dryness/wetness grade by the SPEI.

\section{RESULTS}

\subsection{Water Risk and Climatic Status}

Aqueduct program results show the occurrence of most of the study area under conditions of high water potential (40-50) and there is depletion of groundwater resources due to increase in the population in addition to the extension of agricultural land. Table 2 shows the overall water situation in the province of El-Beheira.

\subsection{Trend Analysis of Precipitation and Evapotranspiration}

For better understand the behavior of the SPI and SPEI indices throughout El-Beheira governorate, a trend analysis for monthly precipitation and evapotranspiration was performed for all weather stations in the period 1950-2010. It's noted that the highest average of the rainfall was recorded in $\mathrm{Al}$ Boseli area (16 mm with \pm 4.2 SEM) and lowest average value was at Badr $(4.7 \mathrm{~mm}$ with \pm 2.35 SEM) Whereas Etay Al Baroud, Wadi ElNatrun and Nubariyah show average values of 6.9, 8.9 and $11.6 \mathrm{~mm}$, respectively. Whereas the highest average of the reference evapotranspiration was at Badr (137.6 mm with \pm 31.9 SEM) while Al Boseli showed the lowest value of the evapotranspiration. The water deficit for Badr, Etay Al Baroud, Wadi El-Natrun, Nubariyah and Al Boseli were 96.6, 94.6, 93.4, 91.2 and 86.9\% respectively. The best model of the historical data of rainfall in selected sites shows a univariate polynomial that can be expressed by the general mathematical equation of the 4 th order polynomial as follows:

$$
P(x)=a_{0}+a_{1} x+a_{2} x^{2}+a_{3} x^{3}+a_{4} x^{4}
$$


Table 1. Categorization of dryness and wetness according to SPI and SPEI

\begin{tabular}{lll}
\hline Category & SPI & SPEI \\
\hline Extremely dry & SPI $\leq-2$ & SPEI $\leq-2$ \\
Severely dry & $-2<$ SPI $\leq-1.5$ & -1.99 to -1.5 \\
Moderately dry & $-1.5<$ SPI $\leq-1$ & -1.49 to -1.0 \\
Near normal & $-1<$ SPI $\leq 1$ & -1.0 to 1.0 \\
Moderately wet & $1<$ SPI $\leq 1.5$ & 1 to 1.49 \\
Severely wet & $1.5<$ SPI $\leq 2$ & 1.50 to 1.99 \\
Extremely wet & SPI $\geq 2$ & SPEI $\geq 2$ \\
\hline
\end{tabular}

Table 2. Coordinates and altitude of the weather stations used in this study, overall water risk, drought severity and ground water stress, according to the Aqueduct online tool (Build date 2013-06-06)

\begin{tabular}{|c|c|c|c|c|c|c|c|}
\hline Station & Altitude & Time series & Latitude & Longitude & Overall water risk & Drought severity & Groundwater stress \\
\hline Etay Al Baroud & 3 & $1950-2010$ & $30^{\circ} 53^{\prime} 33.07^{\prime \prime}$ & $30^{\circ} 38^{\prime} 22.23^{\prime \prime}$ & & & \\
\hline Wadi El-Natrun & 28 & $1950-2010$ & $30^{\circ} 35^{\prime} 42.82^{\prime \prime}$ & $30^{\circ} 14^{\prime} 33.93^{\prime \prime}$ & & & \\
\hline Al Boseli & 0 & $1950-2010$ & $31^{\circ} 20^{\prime} 35.73^{\prime \prime}$ & $30^{\circ} 24^{\prime} 37.98^{\prime \prime}$ & Low to medium risk (1-2) & High (40-50) & Extremely high $(>20)$ \\
\hline Badr & 18 & $1950-2010$ & $30^{\circ} 34^{\prime} 30.43 \prime$ & $30^{\circ} 43^{\prime} 1.12^{\prime}$ & & & \\
\hline Nubariyah & 15 & $1950-2010$ & $30^{\circ} 54^{\prime} 21.16^{\prime \prime}$ & $29^{\circ} 52^{\prime} 15.70^{\prime \prime}$ & & & \\
\hline
\end{tabular}

Table 3. Shows the regression results for the historical rainfall of selected sites, values between brackets refer to the Standard error of the mean $( \pm$ SEM $)$

\begin{tabular}{lllllllll}
\hline Station & ETo & Rainfall & $\mathrm{a}_{0}$ & $\mathrm{a}_{1}$ & $\mathrm{a}_{2}$ & $\mathrm{a}_{3}$ & $\mathrm{a}_{4}$ & $\mathrm{R}^{2}$ \\
\hline Etay Al Baroud & $128( \pm 21.2)$ & $6.9( \pm 2.2)$ & 23.54167 & -14.4437 & 3.642568 & -0.43982 & 0.020651 & 0.994138 \\
Wadi El-Natrun & $134.5( \pm 21.1)$ & $8.9( \pm 2.8)$ & 56.52778 & -32.6105 & 7.330189 & -0.75461 & 0.029611 & 0.994112 \\
Al Boseli & $122.6( \pm 21.2)$ & $16( \pm 4.2)$ & 99.91414 & -54.934 & 11.74886 & -1.16493 & 0.044945 & 0.991220 \\
Badr & $137.6( \pm 31.9)$ & $4.7( \pm 2.35)$ & 27.59848 & -15.0236 & 3.300372 & -0.34079 & 0.013585 & 0.988555 \\
Nubariyah & $132.5( \pm 21.3)$ & $11.6( \pm 4.5)$ & 70.43939 & -39.4359 & 8.576122 & -0.86330 & 0.033727 & 0.997189 \\
\hline
\end{tabular}

where, $\mathrm{P}(\mathrm{x})$ is the 4th-order polynomial, the highest power $\mathrm{n}$ is the order of the polynomial, $\mathrm{a}_{0}, \mathrm{a}_{1}, \mathrm{a}_{2}, \mathrm{a}_{3}$ and $\mathrm{a}_{4}$ are the constant coefficients of the polynomial and are represented in the Table 3 for the different sites.

\subsection{Drought Indices}

\subsubsection{SPI}

The interpolation surface and mapping of SPI of the entire study area which have been resulted from the ordinary Kriging method per 12 month period is closely linked to the above precipitation characteristics. The overall trend is approaching the natural limit of near normal scale by $75.8 \%$. Figure 1 is presenting changes in the dry/wet areas during the 1950-2010 over ElBeheira region. The most significant increasing trend of dryness was found in the west of the region. However, extremely wet years were occurred in 1954, 1964, 1966, 1974 and 2004.

\subsubsection{SPEI}

The analysis of SPEI clearly shows that the recent period of increased drought severity and duration has been unprecedented since 1998 at all stations as depicted in Figure 2. In accordance with the SPI index, extremely dry years were recorded at the 12-month timescale for 2009 and 2010 (SPEI = -2) for all stations. By the descending sorting of stations according to the greatest positive value of SPEI (extremely wet) in terms of the number of the wet years as follows: First station is $\mathrm{Al}$ Boseli (in 1965, 1966, 1975, 1992 and 1993); second station is Nubariyah (in 1985, 1960, 1962 and 1965); third station is Wadi El Natrun (in1965, 1966, 1975, 1992 and 1993); and last stations are Badr and Etay Al Baroud (1965 and 1966). The regression analysis has shown clearly that the values of the SPEI take the direction of a straight reverse line which varies in the values of the slope and interception for the study areas in accordance with the Table 4. Wadi El Natrun and Nubariyah have a greater tendency of $-0.11 \times 10-3$ and followed by Badr and Etay Al Baroud with a tendency of $-0.99 \times 10-4$, whereas Al Boseli has the lower tendency of $-0.59 \times 10-4$. This means that Al Boseli will be less drought-prone areas in the future in comparison with the rest of the regions. 
Amr Mossad et al. / American Journal of Environmental Science 10 (2): 140-147, 2014
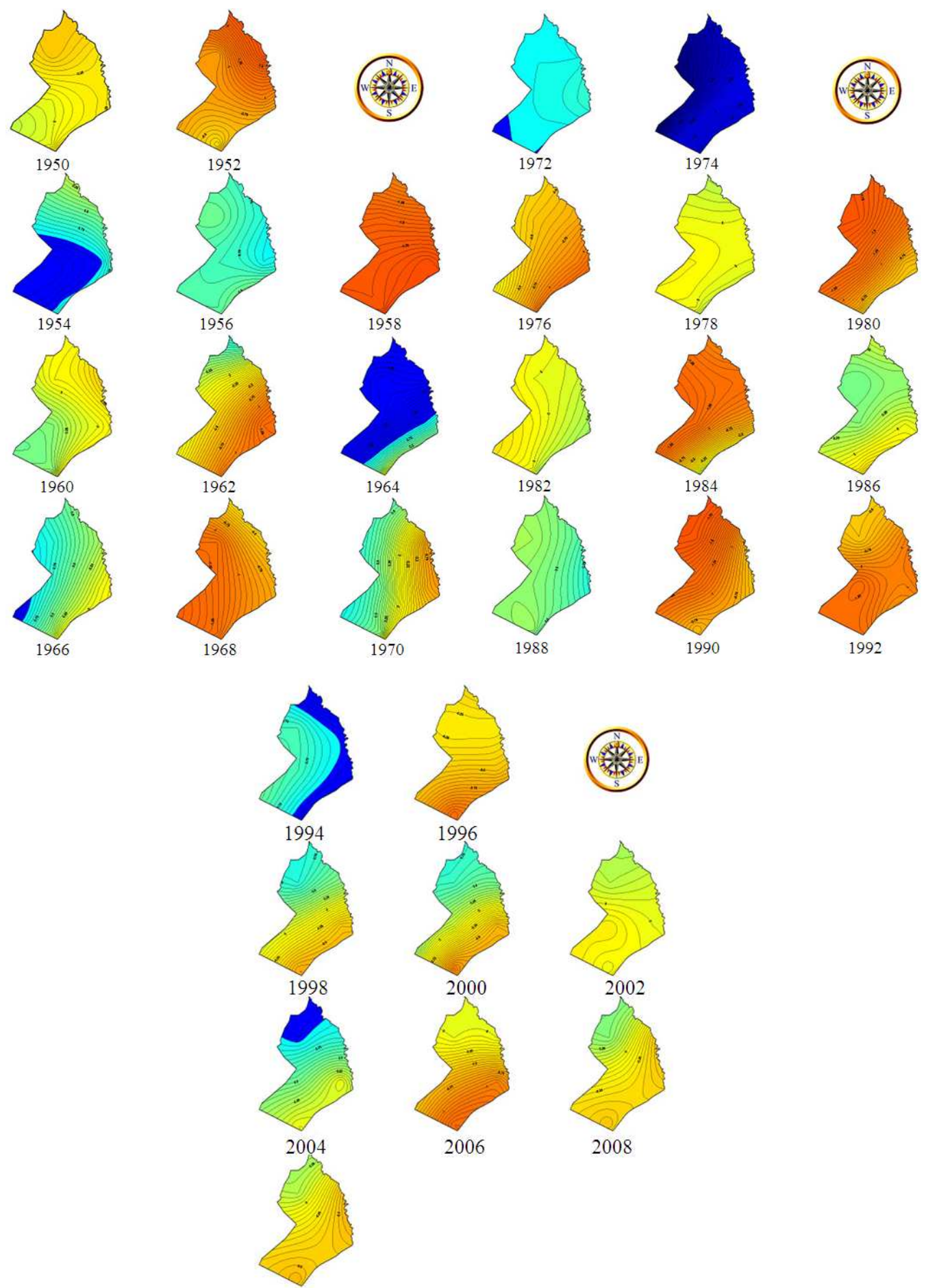

2008

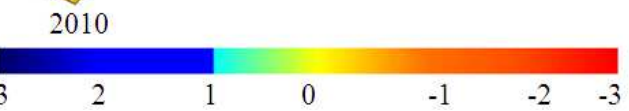

Fig. 1. Composite of 12-month SPI for El-Beheira region 


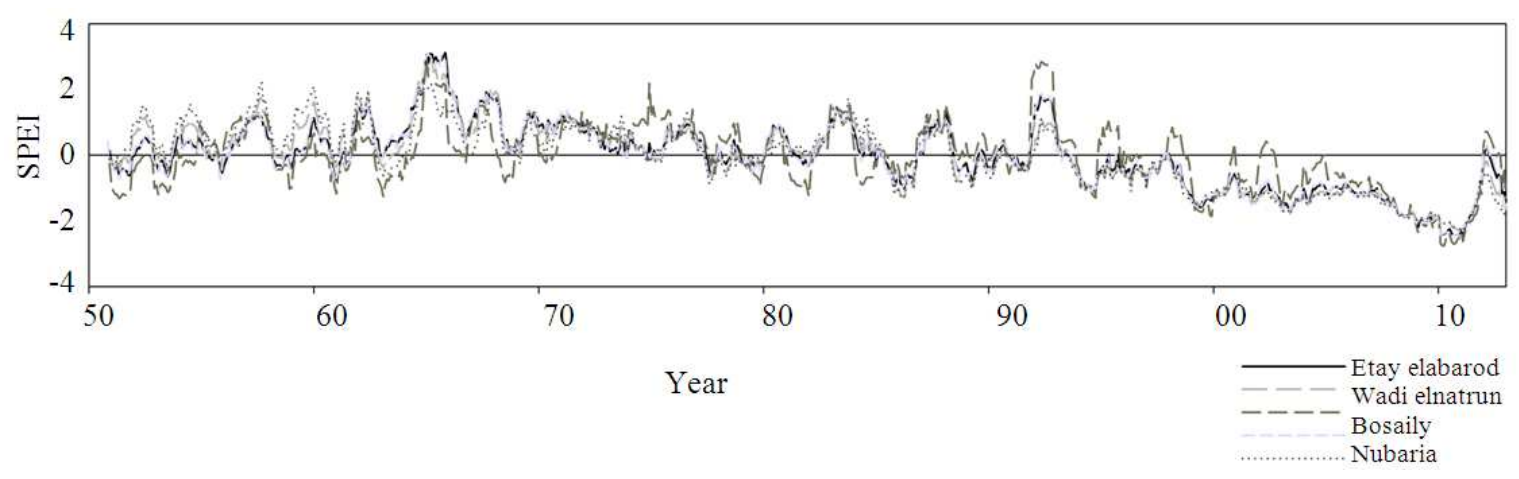

Fig. 2. Evolution of the Annual standardized precipitation evapotranspiration index at 12 month scale (12-SPEI) calculated from the regional data (1950-2010) series of different sites in El-Beheira region

Table 4. Shows the interception and slope of study sites

\begin{tabular}{lccc}
\hline Station & Interception & Slope & R2 \\
\hline Etay Al Baroud & 0.75 & $-0.99 \times 10-4$ & 0.80 \\
Wadi El-Natrun & 0.80 & $-0.11 \times 10-3$ & 0.85 \\
Al Boseli & 0.45 & $-0.59 \times 10-4$ & 0.70 \\
Badr & 0.75 & $-0.99 \times 10-4$ & 0.80 \\
Nubariyah & 0.80 & $-0.11 \times 10-3$ & 0.85 \\
\hline
\end{tabular}

\section{DISCUSSION}

Agricultural water management in Egypt is facing great challenges owing to the Increasing population, growing urbanization and rapid industrialization combined with the highly evapotranspiration. Generally, Data obtained from the aqueduct online tool finds that all stations are currently trend extreme high levels of groundwater stress with high drought stress; this may be part of the drying of the large Mediterranean Basin is related to the strengthening of the anticyclonic circulation and poleward shift of the Atlantic cyclone tracks (Lionello and Giorgi, 2007).

In reference to the results that shows a slight gradual decreasing of the evapotranspiration with increasing of the rainfall values among the sites studied, This variation in the evapotranspiration and rainfall values may be due to the near or far from the Mediterranean Sea which acts as a source of water vapor. There is a clear fluctuation in SPI values over the years at El-Beheira governorate. The Figure 1 shows anomalous values of the SPI during some years, this due to the extreme rainfall that is out of the general trend. Accordingly, SPEI behaves similar way to SPI and therefore the interpretation of the result takes almost the similar trends as the SPI. It can be also observed from the regression analyses of both indices that general trend of the values in all stations are moving in the future toward the drought, this is in accordance with different studies overall the world such as Sonmez et al., 2005 in turkey.

\section{CONCLUSION}

This study highlights the large spatial and seasonal variability of the hydrological response at El-Beheira region to previous climatic conditions. A reduction in precipitation due to climate change affects the severity of droughts. The SPI values show that meteorological drought appears in El-Beheira stations frequently, but in an irregular manner. Accordingly, the SPEI follows the same patterns of the SPI in El-Beheira region with time. They further reveal that, there is no clear relationship between the anomalous values of both indices and different areas of study. Therefore, one of the limitations of this research that El-Beheira region cannot be classified into drought zones and no-drought zones based on the SPI or SPEI anomalies. However, the research prospects do suggest making modifications in these drought indices that could depict the drought condition all over the region for holistic drought strategies in the future studies.

In addition, the above results of the temporal and spatial variability of drought indicate that an urgent and appropriate contingency planning before the onset of severe drought should be implemented in the context of the drought management strategies of Egypt; this will increase resilience to drought that will reflect on the 
economic and social situation of the country.

\section{REFERENCES}

Allen, R.G., L.S. Pereira, D. Raes and M. Smith, 1998. Crop Evapotranspiration: Guidelines for Computing Crop Water Requirements. 1st Edn., Irrigation and Drainage. Rome, ISBN-10: 9251042195, pp: 300.

Al-Qudah, K.A. and A.A. Smadi, 2011. Trends in maximum daily rainfall in marginal desert environment: Signs of climate change. Am. J. Environ. $\quad$ Sci., $\quad$ 7: 331-337. DOI: 10.3844/ajessp.2011.331.337

Aqueduct GIS, 2013. Online tool. Aqueduct GIS.

Gao, M. and X. Hou, 2012. Trends and multifractal analyses of precipitation data from shandong Peninsula, China. Am. J. Environ. Sci., 8: 271-279. DOI: 10.3844/ajessp.2012.271.279

Gibbs, W.J. and J.V. Maher, 1967. Rainfall Deciles as Drought Indicators. 1st Edn., Bureau of Meteorology, pp: 33.

GPCC, 2013. Global Precipitation Climatology Center.

González-Hidalgo, J.C., J.A. Lopez-Bustins, P. Štepánek, J. Martin-Vide and M. De Luis, 2009. Monthly precipitation trends on the Mediterranean fringe of the Iberian Peninsula during the second-half of the twentieth century (1951-2000). Int. J. Climatol., 1 29: 1415-1429. DOI: $10.1002 /$ joc. 1780

Hamdi, M.R., M. Abu-Allaban, A. Al-Shayeb, M. Jaber and N.M. Momani, 2009. Climate change in jordan: A comprehensive examination approach. Am. J. Environ. Sci., 5: 58-68. DOI: 10.3844/ajessp.2009.58.68

Hayes, M., M. Svoboda, N. Wall and M. Widhalm, 2011. The Lincoln declaration on drought indices: Universal meteorological drought index recommended. Bull. Am. Meteorol. Soc., 92: 4858. DOI: $10.1175 / 2010$ BAMS3103.1

Heim, R.R., 2002. A review of 20th-century drought indices used in the United States. Bull. Am. Meteorol. Society, 83: 1149-66.

Helsel, D.R. and R.M. Hirsch, 1992. Statistical Methods in Water Resources. 1st Edn., Elsevier, Amsterdam, ISBN-10: 0080875084, pp: 548.

Hosking, J.R.M. and J.R. Wallis, 1997. Regional Frequency Analysis: An Approach Based on L-moments. 1st Edn., Cambridge University Press, Cambridge, ISBN10: 0521430453, pp: 224.
Keyantash, J. and J.A. Dracup, 2004. An aggregate drought index: Assessing drought severity based on fluctuations in the hydrologic cycle and surface water storage. Water Resources Res., 40: W09304W09304. DOI: 10.1029/2003WR002610

Kogan, F.N., 2002. World droughts in the new millennium from AVHRR-based Vegetation Health Indices. Eos, Trans. Am. Geophys. Union, 83: 562563. DOI: $10.1029 / 2002 E O 000382$

Lionello, P. and F. Giorgi, 2007. Winter precipitation and cyclones in the Mediterranean region: Future climate scenarios in a regional simulation. Adv. Geosci., 12: 153-158. DOI: 10.5194/adgeo-12-1532007

Loukas, A., L. Vasiliades and J. Tzabiras, 2007. Evaluation of climate change on drought impulses in Thessaly, Greece. Eur. Water, 17/18: 17-28.

López-Moreno, J.I., T.M. Hess and S.M. White, 2009. Estimation of reference evapotranspiration in a mountainous Mediterranean site using the PenmanMonteith equation with limited meteorological data. Pirineos, 164: 7-31.

McKee, T.B., N.J. Doesken and J. Kleist, 1993. The relation of drought frequency and duration to time scales. Proceedings of the 8th Conference on Applied Climatology, Jan. 17-22, Anaheim, California, pp: 179-184.

Mimikou, M.A.,Y.S. Kouvopoulos and P.S. Hadjissawa, 1993. An analysis of multiyear droughts in Greece. Int. J. Water Resources Dev., 9: 281-291. DOI: 10.1080/07900629308722589

Mishra, A.K. and V.P. Singh, 2010. A review of droughtconcepts. J. Hydrol., 391: 202-16. DOI: 10.1016/j.jhydrol.2010.07.012

Mo, K.C., 2011. Drought onset and recovery over the united states. J. Geophys. Res., 116: D20106. DOI: 20110.21029/22011JD016168.

Nkemdirim, L. and L. Weber, 1999. Comparison between the droughts of the 1930s and the 1980s in the Southern Prairies of Canada. J. Climate, 12: 2434-2450. DOI: $10.1175 / 1520$ 0442(1999)012<2434:CBTDOT>2.0.CO;2

Palmer, W.C., 1968. Keeping track of crop moisture conditions, nationwide: The new crop moisture index. Weatherwise, 21: 156-161. DOI: 10.1080/00431672.1968.9932814

Samdi, M.M and A. Zghoul, 2006. A sudden change in rainfall characteristics in amman, Jordan during the mid 1950s. Am. J. Environ. Sci., 2: 84-91. DOI: 10.3844/ajessp.2006.84.91 
Shafer, B.A. and L.E. Dezman, 1982. Development of a Surface Water Supply Index (SWSI) to assess the severity of drought conditions in snowpack runoff areas. Proceedings of the 50th Annual Western Snow Conference, (SC '82), Fort Collins, CO, pp: 164-175.

Shukla, S. and A.W. Wood, 2008. Use of a standardized runoffindex for characterizing hydrologic drought. Geophysical Res. Lett., 35: L02405. DOI: 10.1029/2007GL032487

Sprent, P. and N.C. Smeeton, 2001. Applied Nonparametric Statistical Methods. 3rd Edn., Chapman and Hall/CRC, Boca Raton, ISBN-10: 1584881453, pp: 461.

Svoboda, M., D. LeComte, M. Hayes, R. Heim and K. Gleason, 2002. The droughtmonitor. Bull. Am. Meteorol. Society, 83: 1181-90.
Thornthwaite, C.W., 1948. An approach toward a rational classification of climate. Geographical Rev., 38: 55-94. DOI: 10.2307/210739

Valentina, K., V. Tobias and H. Fred, 2008. Detection of change in drought frequency in the Elbe basin: Comparison of three methods. Hydrol. Sci. J., 53: 519-537. DOI: 10.1623/hysj.53.3.519

Vicente-Serrano, S.M., 2006. Evaluating the impact of drought using remote sensing in a Mediterranean, semi-arid region. Nat. Hazards, 40: 173-208. DOI: 10.1007/s11069-006-0009-7

Vicente-Serrano, S.M., S. Beguersa andJ.I. LpezMoreno, 2010. A multi-scalar drought index sensitive to global warming: The standardized precipitation evapotranspiration index-SPEI. J. Climate, 23: 1696-1718. DOI: 10.1175/2009JCLI2909.1 